\title{
In-situ Decomposition of Trichloroethylene Using Electrochemical Treatment Method
}

\author{
Takuya Ito ${ }^{1}$, Kazuyuki Yamada ${ }^{1}$, Sigeru Kato ${ }^{1}$, Hideki Suganuma $^{1}$, Akihiro Yamasaki $^{1}$, Seiichi Suzuki ${ }^{1}$ \& \\ Toshinori Kojima ${ }^{1}$ \\ ${ }^{1}$ Department of Materials and Life Science, Seikei University, Tokyo, Japan \\ Correspondence: Takuya Ito, Department of Materials and Life Science, Seikei University, 3-3-1 \\ Kichijoji-kitamachi, Musashino-shi, Tokyo, Japan. Tel: 81-422-37-3733. E-mail: takuya.ito@st.seikei.ac.jp
}

$\begin{aligned} & \text { Received: November 30, } 2013 \\ & \text { Accepted: March 20, } 2014 \quad \text { Online Published: April 30, } 2014 \\ & \text { doi:10.5539/eer.v4n2p90 }\end{aligned}$ URL: http://dx.doi.org/10.5539/eer.v4n2p90

\begin{abstract}
Trichloroethylene (TCE) has an excellent degreasing capacity, so it is often used as a solvent for dry cleaning, and is still used for removing grease from metallic parts and so on. However, its inappropriate handling caused contamination of soil. Recently, its toxicity and carcinogenicity to humans have been concerned. By these reasons, it is highly required to remediate the contaminated soils. In the present study, the possibility of application of electrochemical treatment method to the in-situ decomposition of TCE is examined because in-situ remediation is expected to be simple and inexpensive. The experiment in the aqueous systems was conducted as a basic examination. As a result of comparing experimental values under various stirring speeds with the theoretical value calculated from mass transfer coefficient, it turned out that TCE transferring from bulk to the electrode surface is accelerated by the radicals in the boundary film near the electrode surface. Hence the TCE decomposition rate is affected by the radical formation rate or radical concentration in the boundary film. In the experiment with the soils, the TCE decomposition rate was much smaller than that in the aqueous systems. Moreover, the influence of the voltage was not observed. Therefore, it turned out that the movement of TCE in the aqueous phase near the electrode surface was the rate-controlling step in the soils. Under the condition, the TCE decomposition rate was not affected by the particle size. Consequently, it turned out TCE is not transported by bulk flow but is mostly transfered by molecular diffusion in the soil.
\end{abstract}

Keywords: trichloroethylene, electrochemical treatment, in-situ decomposition, contamination of soil, electroosmosis

\section{Introduction}

Trichloroethylene (TCE) has an excellent decreasing capacity, so it is often used as a solvent for dry cleaning, and is still used for removing grease from metallic parts and so on. However, its inappropriate handling caused contamination of soil and ground water (Fan, 1988). Recently, its toxicity and carcinogenicity to humans have been concerned. By these reasons, it is highly required to clean contaminated soils and ground water (Chemicals Evaluation and Research Institute, Japan, 2006). Though the aeration method has often been used up to now for cleaning contaminated soils, its high remediation cost is one of the serious problems (Komatsu, 2005). In the present study, the possibility of application of electrochemical treatment method to the in-situ decomposition of TCE is examined because in-situ remediation is expected to be simple and inexpensive. Electroosmotic flow is the motion of liquid induced by an applied potential across porous materials, capillary tubes, membranes, microchannels, and any other fluid conduits. Because electroosmosis method has the following advantages, it is expected to be used for in-situ cleaning of the contaminated soil. Especially, it can be applied to the soils with low water permeability such as clay and silt. Furthermore, the combination of this method with other purification ones is easy (Ninae et al., 2001, 2005; Athmer et al., 1994). Moreover, the decomposition of the pollutant using radicals from various electrochemical reactions produced at the electrode surface is reported (Wang \& Lemley, 2002). When water is electrically decomposed by using the stable electrode, oxygen and radical compound are generated in the anode. Although the life time of this radical compound is very short, its strong oxidizing power is expected to be strong enough to decompose persistent substances.

The authors have reported that TCE is decomposed by the electro degradation simultaneously with the electroosmosis (Matsumura et al., 2001). The experiment was conducted in the solution as a basic examination 
of the electroosmosis method. However, the ascertainment of the effectiveness of this method in the soil has not so far been conducted. In the present study, the experiment in the artificial soil was conducted as a simulation of remediation of contaminated soil.

\section{Material \& Method}

\subsection{TCE Decomposition in Solution}

One thousand $\mathrm{mL}$ of various concentrations $(0.05-1.0 \mathrm{mmol} / \mathrm{L})$ of the aqueous solution of potassium nitrate including TCE $(4.0 \mathrm{mmol} / \mathrm{L})$ was prepared for 180 minute test at $15^{\circ} \mathrm{C}$ in a glass vessel $(100 \mathrm{~mm} \times 100 \mathrm{~mm} \times$ $200 \mathrm{~mm}$ ). The platinum (anode) and the stainless (cathode) plates were used as the electrodes. The electric power with various currents was applied under the constant current condition and the voltages were read and $3 \mathrm{ml}$ of the solution was sampled from the reactor at regular intervals. The residual TCE was extracted from the solution with $15 \mathrm{ml}$ of $\mathrm{n}$-hexane $(5 \mathrm{ml} \times 3)$. It is confirmed that all TCE is extracted with this amount of $\mathrm{n}$-hexane in the preliminary experiment. The n-hexane solution was dehydrated with anhydrous sodium sulfate. The concentration of the residual TCE in the n-hexane solution was quantified by a gas chromatograph with an electron capture detector (GC-ECD). The experimental apparatus chart used is shown in Figure 1.

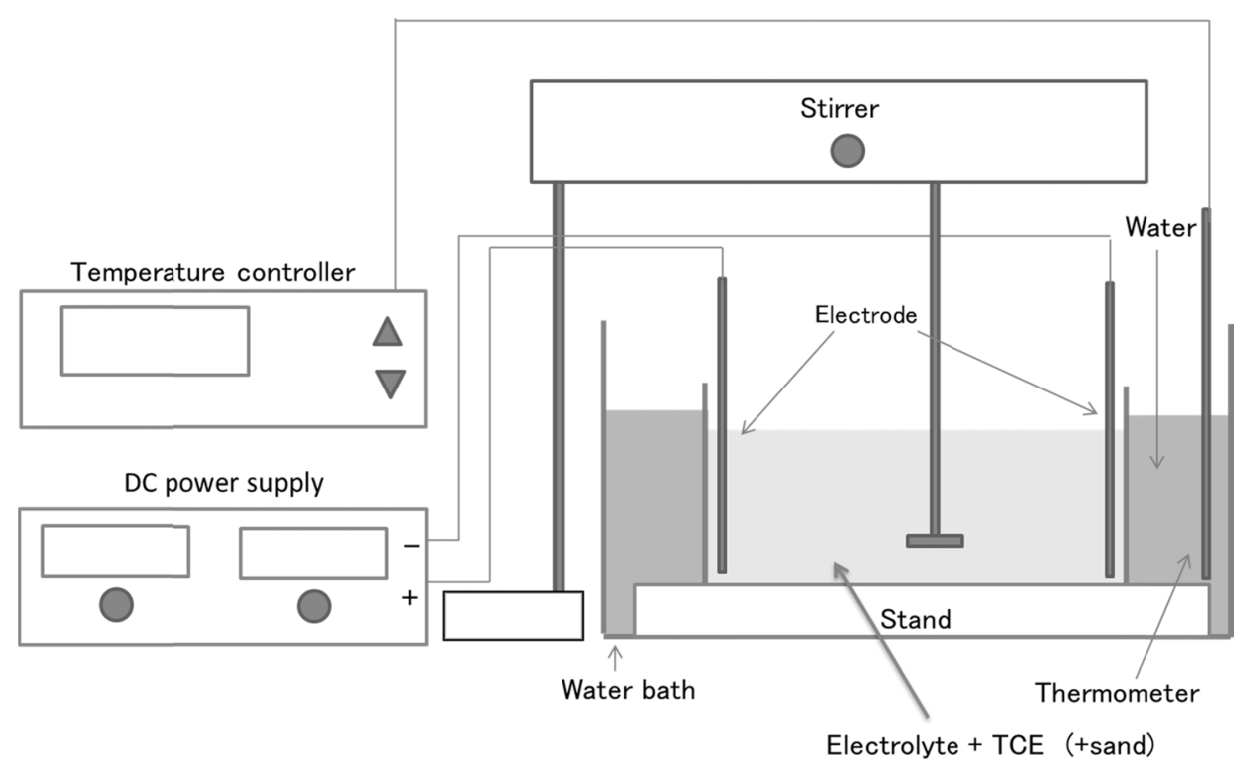

Figure 1. Experimental setup of electro degradation

\subsection{TCE Decomposition in Soil}

Same vessel as above was used in this experiment. The same vessel as above was packed with $1000 \mathrm{~mL}$ of aritificial soil (Silica sand, bed voidage 34.0\%; Glass bead, bed voidage 40.4\%). Various concentrations $(0.05-1.0 \mathrm{mmol} / \mathrm{L})$ of the aqueous solution of potassium nitrate including TCE $(4.0 \mathrm{mmol} / \mathrm{L})$ was poured until the void of the soil was saturated in the reactor filled with artificial soil. The experiments were conducted under the condition similar to the above condition for solution only, excepting that soil layer was not stirred. The solution was energized at various constant currents. Three $\mathrm{mL}$ of solution in the soil was sampled from three places (the vicinity of anode, the center and the vicinity of cathode) by $10 \mathrm{~g}$ at regular intervals. The residual TCE in the soil was extracted by acetonitrile $20 \mathrm{ml}$ and water $10 \mathrm{ml}$, and the TCE concentration was determined as above.

\section{Result and Discussion}

\subsection{TCE Decomposition in Solution}

An example of time variation of residual TCE [wt \%] by electrical decomposition is shown in Figure 2 . The reaction path through which the hydroxide radical generated from the electro degradation of water decomposes TCE is reported as follows (Yoshida, 2008; Lu et al., 2009)

$$
\begin{aligned}
& \mathrm{H}_{2} \mathrm{O} \longrightarrow \mathrm{OH}^{\cdot}+\mathrm{H}^{+}+\mathrm{e}^{-} \\
& \mathrm{TCE}+\mathrm{OH}^{\cdot} \longrightarrow \text { products }
\end{aligned}
$$


The theoretical value of time for complete decomposition of TCE was calculated assuming the above stoichiometric equation, namely one mol of TCE is decomposed by one Faraday of electricity. Namely it proceeds by the zero-order reaction kinetics. Under the condition of initial TCE concentration of $4.0 \mathrm{mmol} / \mathrm{L}$ and current of $100 \mathrm{~mA}$, the time for complete decomposition of TCE was calculated to be about $64 \mathrm{~min}$, using the aqueous volume of $1 \mathrm{~L}$. This calculated value is the time when the added electric quantity reaches $4.0 \mathrm{mF}$ because $1 \mathrm{~F}$ is necessary to decompose TCE of $1 \mathrm{~mol}$. As shown from Figure 2, the $60 \%$ of TCE remains at the reaction time of 60 minutes. It is suggested that the ratio of TCE reacted to the applied electron was less than unity under the actual condition, which is caused by that the electro degradation of water is a primary reaction and that life time of hydroxide radicals is short.



Figure 2. An example of time variation of residual TCE by electrical decomposition in water (current, $100 \mathrm{~mA}$ : $\mathrm{KNO}_{3}$ Concentration, $0.10 \mathrm{M}$ )

Hence, this reaction thereafter was calculated as a first-order reaction which well described the progress of the TCE decomposition reaction. First-order reaction rate constant, $k$, was obtained from the slope of the regression line on semi-log plot of residual TCE concentration, $C_{T C E}$, vs. reaction time, $t$, according to the following equation.

$$
\ln \left(C_{T C E} / C_{T C E, 0}\right)=-k t
$$

The effect of the potassium hydroxide concentration on the relationship between the first order rate constant and applied current is shown in Figure 3 under the constant current. The resulted voltage and power are also calculated and the observed rate constant data are also plotted against them respectively in Figures 4 and 5. 


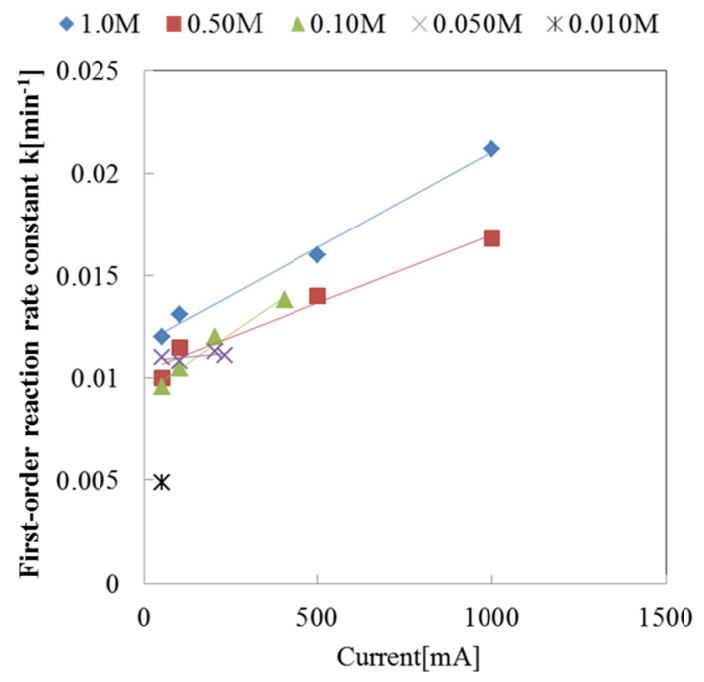

Figure 3. Electro degradation of TCE in water (Constant current condition)

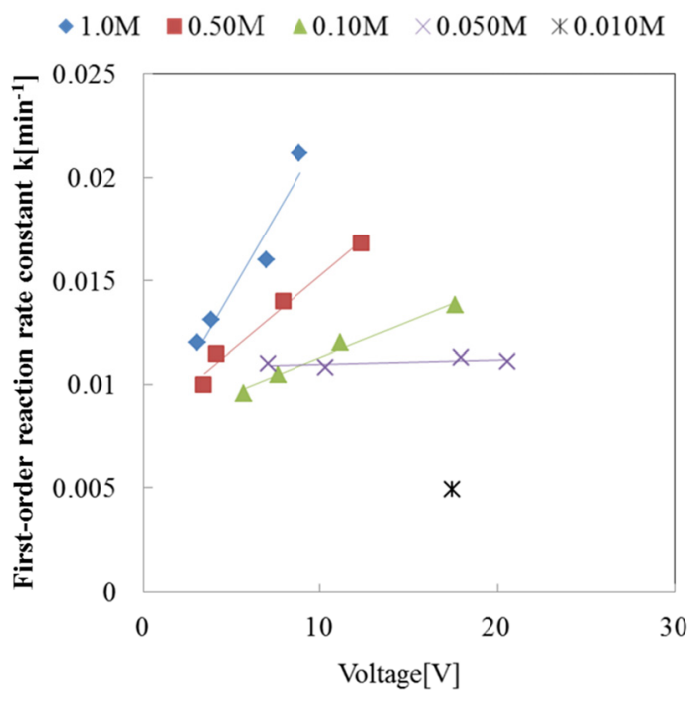

Figure 4. Electro degradation of TCE in water (Constant current condition shown in Figure 3)

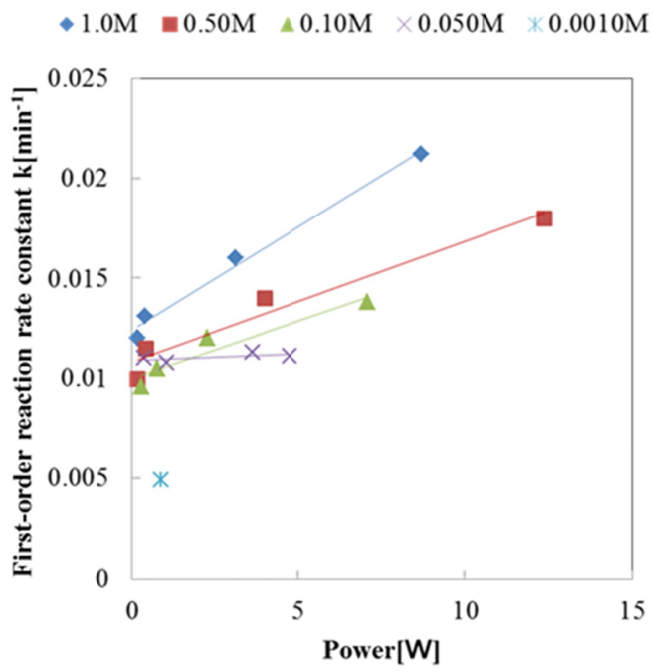

Figure 5. Electro degradation of TCE in water (Constant current condition shown in Figure 3) 
As shown from Figures 3-5, the TCE decomposition rate was increased with an increase in electric strength condition and the increased electrolyte concentration increased the rate of reaction. Therefore, it was thought that the radical formation speed on the electrode surface is rate-determining step or the transfer rate of TCE is accerelated by the increased radical concentration.

Next, the effect of the stirring speed on the relation between the concentration of TCE and reaction time was shown in Figure 6. The theoretical values of mass transfer rate of TCE calculated using the Johnson-Huang equation and the Wilke-Chang equation are also shown as straight lines in Figure 6 for comparison. The Johnson-Hung equation for the boundary film mass transfer estimation, the Wilke-Chang equation for diffusion coefficient estimatin, and the differential equation used for theoretical prediction are shown below. In the cause of the calculation of Equation 2, we approximately used $0.1 \mathrm{~m}$ for the diameter of reactor, $\mathrm{D}_{\mathrm{T}}$, though our reactor was rectangular and transfer area is vertical while the reactor of Johnson \& Huang was cylindrical and transfer area is horizontal and accordingly, the absolute value of mass transfer rate might be different.

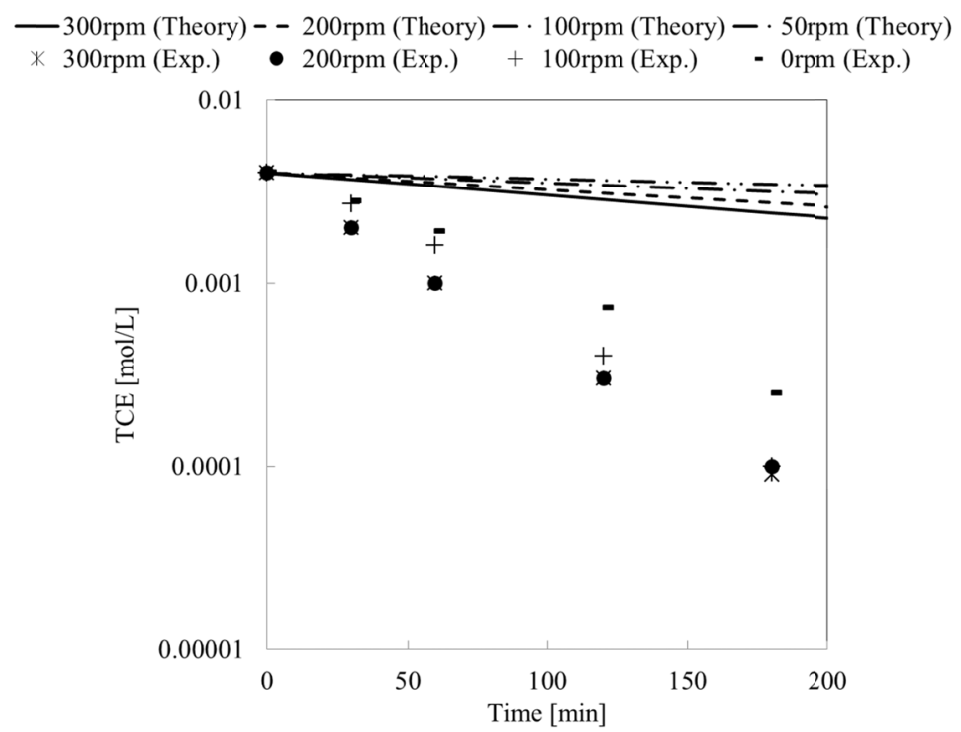

Figure 6. Comparison of experimental results and theoretical values assuming boundary film mass transfer control

$<$ Johnson-Hung equation (Johnson \& Huang, 1956) $>$

$$
\mathrm{Sh}=0.0924 \mathrm{Re}^{0.71} \mathrm{Sc}^{0.5}
$$

$<$ Equation of dimensionless number $>$

$$
\begin{aligned}
& \text { Sherwood number: } \mathrm{Sh}=\frac{\mathrm{k}_{\mathrm{L}} \mathrm{D}_{\mathrm{T}}}{\mathrm{D}_{\mathrm{A}}} \\
& \text { Reynolds number: } \mathrm{Re}=\frac{\mathrm{d}^{2} \mathrm{n} \rho}{\mu} \\
& \text { Schmid number: } \mathrm{Sc}=\frac{\mu}{\rho \mathrm{D}_{\mathrm{A}}}
\end{aligned}
$$

$<$ Wilke-Chang equation (Wilke \& Chang, 1955) $>$

$$
\mathrm{D}_{\mathrm{A}}=\frac{7.4 \times 10^{-8}\left(\beta \mathrm{M}_{\mathrm{H}_{2} \mathrm{O}}\right)^{0.5} \mathrm{~T}}{\mu \mathrm{V}_{\mathrm{m}}{ }^{0.6}}
$$

$<$ Equation of theoretical value $>$

$$
-\mathrm{V} \frac{\mathrm{dC}_{\mathrm{TCE}}}{\mathrm{dt}}=\mathrm{k}_{\mathrm{L}} \mathrm{AC}_{\mathrm{TCE}}
$$


Or solution

$$
\begin{gathered}
\ln \frac{\mathrm{C}_{\mathrm{TCE}}}{\mathrm{C}_{\mathrm{TCE}, 0}}=-\frac{\mathrm{A}}{\mathrm{V}} \mathrm{k}_{\mathrm{L}} \mathrm{t} \\
\mathrm{C}_{\mathrm{TCE}}=\mathrm{C}_{\mathrm{TCE}, 0} \mathrm{e}^{-\frac{\mathrm{Ak}_{\mathrm{L}}}{\mathrm{V}}}
\end{gathered}
$$

$k_{L}$ : Mass transfer coefficient, $\mathrm{m} / \mathrm{s}$

$D_{T}$ : Diameter of reactor, $\mathrm{m}$

$D_{A}: \quad$ Diffusion coefficient of TCE, $\mathrm{m}^{2} / \mathrm{s}$

$d$ : $\quad$ Diameter of stirring blade, $\mathrm{m}$

$n: \quad$ Rotating speed (in rps), $\mathrm{s}^{-1}$

$\rho: \quad$ Density of the solution, $\mathrm{kg} / \mathrm{m}^{3}$

$\mu$ : $\quad$ Viscosity of solution, $\mathrm{Pa} \cdot \mathrm{s}(\mathrm{cP}=\mathrm{mPa} \cdot \mathrm{s}$, only

in Equation (6)) $\beta: \quad$ Association coefficient, -

$M_{\mathrm{H}_{2} \mathrm{O}}$ : Molecular weight of water, $\mathrm{g} / \mathrm{mol}$

$V_{m}:$ Molar volume of TCE, $\mathrm{cm}^{3} / \mathrm{mol}\left(=10^{-6} \mathrm{~m} / \mathrm{mol}\right)$

$C_{T C E}:$ TCE concentration at time $\mathrm{t}, \mathrm{mol} / \mathrm{m}^{3}$

$C_{T C E, 0}:$ TCE initial concentration, $\mathrm{mol} / \mathrm{m}^{3}$

A: $\quad$ Surface area of electrode, $\mathrm{m}^{2}$

$t: \quad$ Time, $\mathrm{s}$

$V: \quad$ Volume of liquor, $\mathrm{m}^{3}$

\section{$T$ : $\quad$ Temperature, $\mathrm{K}$}

As shown from Figure 6, the stirring speed did not influence the decomposition rate of TCE under the present experimental condition while the theoretical decomposition rate of TCE increases with an increase in the stirring speed under the condition of film mass transfer control. Therefore, the rate-determining step of the electro degradation of TCE is not the simple transport of TCE in the film. Considering the experimental decomposition rate was much faster than that of the predicted value under the mass transfer control, it is suggested that the diffusion of TCE in the film is accelerated by the electrically radicals and it is the rate controlling step. Consequently, it is thought that the electro degradation rate of TCE was influenced by the electric condition.

\subsection{TCE Decomposition in Soil}

Effect of voltage on the relationship between reaction time and residual TCE concentration in electro degradation of TCE in the soil (quartz sand) is shown in Figure 7. The slope of the fitting line gives the apparent first-order reaction rate constant. For comparison, the result in solution is also shown in Figure 7. As shown from Figure 7, the decomposition rate in the soil doesn't increase even with increased voltage. In addition, the decomposition rate of TCE in the soil (sand) is slower than that in the solution. It is thought that TCE is not sufficiently supplied to the electrode surface by mass transfer resistance in the soil, though the electro-osmotic flow may be caused in the soil.

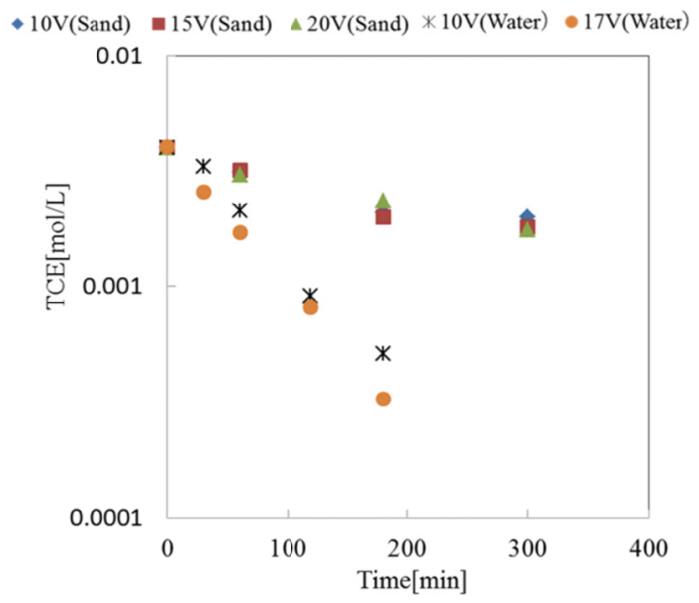

Figure 7. Electro degradation of TCE in soil

Next, effect of particle size in the soil layer on the time variation of residual TCE concentration in electro degradation of TCE is shown in Figure 8. As shown from Figure 8, the TCE decomposition rate is almost equal 
in the both cases with quartz sand $(156 \mu \mathrm{m})$ and glass bead $(386 \mu \mathrm{m})$ used as artificial soil. Considering that the resistance of bulk flow is affected by the particle diameter, while diffusion is mainly affected by the voidage, it turned out that TCE is not transported by bulk flow but is mostly transferred by molecular diffusion in the voidage of the space under the actual experiment condition. The reason why the same results are given for both of soils is explained by the fact that not only the effective diffusion coefficient but also the volume of the solution is proportional to the voidage, leading to the same time variation of concentration of TCE in the soil bed void.

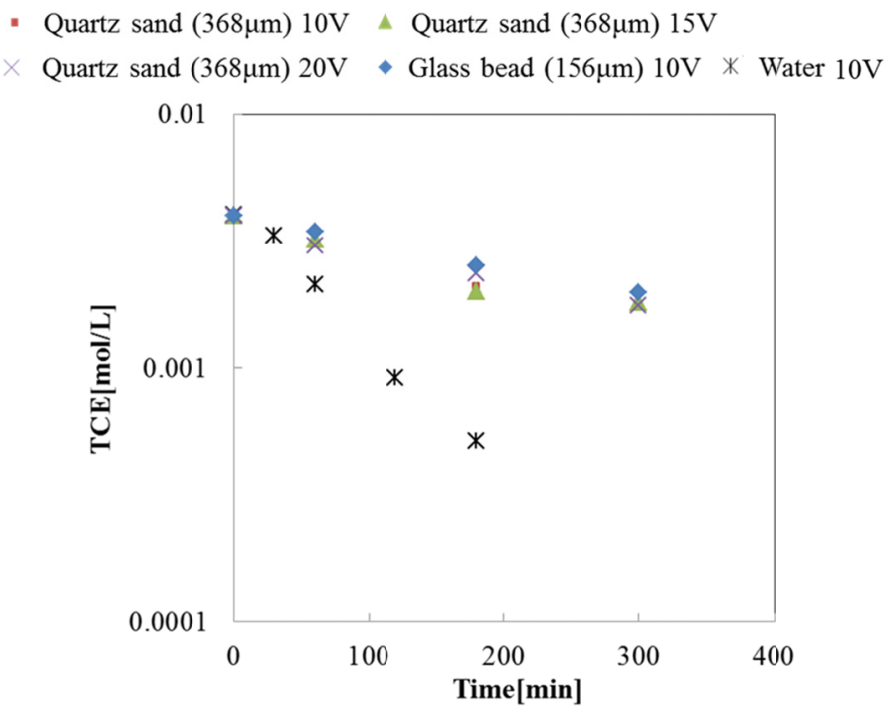

Figure 8. Influence of difference in particle diameter

\section{Conclusion}

In-situ decomposition of TCE using the electrochemical treatment method in the solution and in the soil was investigated. The following characteristics of the reaction were suggested.

1) The rate-determining step of the electro degradation of TCE is not simple diffusion of TCE in boundary film but is the accelerated by the decomposition of TCE by radicals formed at or near the electrode surface. Therefore, an increase of the electrolyte concentration and an increase in the electric power are effective.

2) In the electro degradation of TCE in the soil, the transportion of TCE to the electrode surface is the rate-determining step, and the TCE decomposition rate is much slower than that in solution. Moreover, it turned out that TCE is not transported by bulk flow but is mostly transfered by molecular diffusion in the soil.

\section{References}

Athmer, C. J., Ho, S. V., \& Sheridan, P. W. (1994). Laboratory Study of the Movement of Trichloroethylene through Clayey Soils by Electroosmosis. Proc Annu Meet Air Waste Manag Assoc, 87(14), 1-16.

Chemicals Evaluation and Research Institute, Japan. (2006). HAZARD ASSESSMENT REPORT Trichloroethylene. Tokyo: Chemicals Evaluation and Research Institute, Japan.

Fan, A. M. (1988). Trichloroethylene: water contamination and health risk assessment. In Reviews of environmental contamination and toxicology (pp. 55-92). Springer New York.

Johnson, A. I., \& Huang, C. J. (1956). Mass transfer studies in an agitated vessel. AIChE Journal, 2(3), $412-419$. http://dx.doi.org/10.1002/aic.690020322

Komatsu, T., \& Møldrup, P. (2005). The emerging role of soil physics in environmental engineering. Journal of the Japanese Society of Soil Physics, 100, 5-14.

Lu, X., \& Yuan, S. (2009). Electrokinetic removal of chlorinated organic compounds. In K. R. Reddy \& C. Cameselle (Eds.), Electrochemical Remediation Technologies for Polluted Soils, Sediments and Groundwater (pp. 219-234). Hoboken, New Jersey: John Wiley \& Sons, Inc. 
http://dx.doi.org/10.1002/9780470523650.ch10

Matsumura, M., \& Kojima, T. (2001). Decomposition of trichloroethylene in soil by electric osmosis. Kagaku Kogaku Ronbunshu, 27(1), 1-6. http://dx.doi.org/10.1252/kakoronbunshu.27.1

Niinae, M., Aoki, Y., \& Aoki, K. (2005). Numerical Modeling for Electrokinetic Soil Processing-Acidification of Soil. Journal Code: F0195A, 52(3), 136-144.

Ninae, M., Sugano, T., Aoki, K., \& Yasuda, T. (2001). A Study on Contaminant Removal from Soil by Coupled Electric. Hydraulic Gradient. Resources Processing, 48(3), 176-183. http://dx.doi.org/10.4144/rpsj1986.48.176

Wang, Q., \& Lemley, A. T. (2002). Oxidation of carbaryl in aqueous solution by membrane anodic Fenton treatment. Journal of Agricultural and Food Chemistry, 50(8), 2331-2337. http://dx.doi.org/10.1021/jf011434w

Wilke, C. R., \& Chang, P. (1955). Correlation of diffusion coefficients in dilute solutions. AIChE Journal, 1(2), 264-270. http://dx.doi.org/10.1002/aic.690010222

\section{Copyrights}

Copyright for this article is retained by the author(s), with first publication rights granted to the journal.

This is an open-access article distributed under the terms and conditions of the Creative Commons Attribution license (http://creativecommons.org/licenses/by/3.0/). 